\title{
Editorial
}

\section{Crosscutting issues in education}

Interdisciplinary Research in Education

2021, Vol 6, No. I, pp i-ii

DOI: https://doi.org/10.3126/ire.v6i1.43523

Higher education institutions play a greater role in pushing the frontier of knowledge, and as a result, the domain of scholarships has been extended at a greater speed than ever before. The boundary of subject-specific knowledge has become slender and porous with the growth of interdisciplinary and cross-cutting scholarships. As societies become complex and the workplace requires employees with multitasking skills, the need for multidisciplinary and interdisciplinary knowledge has been paramount in both academia and the workplace. The Interdisciplinary Research in Education (IRE) creates a common platform where researchers from various disciplines bring significant issues and knowledge from their studies and contribute to both policies and praxis of education. This volume particularly connects crosscutting knowledge and scholarships from subject-specific as well as interdisciplinary and cross-cutting areas of pedagogy and research.

Primarily, this volume addresses issues of curriculum, teaching and technology. With the rise of the application of technology in school and higher education, there is a great demand for integrating ICT into classroom activities. This requires teachers to be equipped with both technological and pedagogical skills to deliver lessons effectively through ICT-based applications. In addition, there is a need for the revision of the curriculum, content, pedagogy, and assessment to suit the technology-driven management of learning. Further, we have been delivering lessons through open and distance mode and a considerable number of students are benefiting from this alternative approach of teaching. However, there are several challenges faced by both providers and learners while working through a virtual mode. Two articles in this volume contribute to this field.

As a cross-cutting area of learning, issues of inclusion are crucial. Several works have been done at Tribhuvan University addressing the issues of gender and indigenous knowledge in higher education. An article in this volume draws upon a research-based work and analyzes a university curriculum looking at how the curriculum and pedagogical practices address the issues of gender and inclusion. Classroom management and assessment are pertinent issues, and two articles focus on these pragmatic issues. How effective classroom management helps teachers select appropriate pedagogical strategies and tools is the major scholarly contribution of the first work. Through an empirical study, the next work highlights how teachers understand and apply various strategies of assessment in Nepali schools. 
Translanguaging is an emerging issue in language education. Drawing on field-based research, an article in this volume reveals that translanguaging makes the learners interactive in the classroom through which they develop critical and creative thinking skills. Parental financing in higher education is another interdisciplinary work that this volume deals with. Through a study among 120 students at Tribhuvan University, an article in this volume highlights the amount and trend of student expenditure in higher education in Nepal. Interestingly, this study reveals that female students spend $20 \%$ more than their male counterparts. Touching upon the issue of adolescents' sexual and reproductive health and using the information from Nepal Demographic and Health Survey 2016, another work in this volume shares the findings related to marriage, sexual relationship, fertility, family planning, maternal and knowledge on abortion, physical and sexual violence. The role of pilgrimage education in tourism and its implications for tourism education is discussed in another article of this volume. This work is based upon a survey among pilgrims in Pashupatinath Temple in Kathmandu.

Two other works contribute to the methodology of qualitative research. The practical strategy of revealing personal stories and restoring them through a thematic and narrative analysis process is the key contribution of the first work. Based on his doctoral research experience, the author of the second work highlights how a researcher's worldview and his/her ontological, epistemological, and methodological position help the researcher to select appropriate research design and data generating instruments. In this interdisciplinary volume, the final four articles, written in Nepali, contribute to linguistics and pragmatic issues of research and pedagogy at the master's degree study at Tribhuvan University. While the first article discusses the issues of keyword entries in Nepali dictionaries, the other two highlight the issues of using APA guidelines in the thesis and theoretical and pragmatic issues of writing the abstract in the theses written in Nepali languages. The final article explores the problems related to underachievement in the semester system at Tribhuvan University and the underlying factors that contribute to the poor performance of the learners. Overall, this volume contributes to multidisciplinary and interdisciplinary knowledge in education, bringing significant findings from field-based research, raising critical policy issues, and offering recommendations for resolving challenges and improving practice.

Peshal Khanal Professor of Education 